\title{
Procedure Agent Dose per Administration
}

National Cancer Institute

\section{Source}

National Cancer Institute. Procedure Agent Dose per Administration. NCI Thesaurus.

Code C162123.

The dose of study procedure agent taken per administration. 